Research Article

\title{
Optimization Design of a New Type of Interior Permanent Magnet Generator for Electric Vehicle Range Extender
}

\author{
Shilun Ma $\mathbb{D}^{1},{ }^{1}$ Xueyi Zhang $\mathbb{D}^{1},{ }^{1}$ Qinjun Du, ${ }^{2}$ Liwei Shi, ${ }^{1}$ and Xiangyu Meng ${ }^{1}$ \\ ${ }^{1}$ School of Transportation and Vehicle Engineering, Shandong University of Technology, Zibo 255049, China \\ ${ }^{2}$ School of Electrical and Electronic Engineering, Shandong University of Technology, Zibo 255049, China \\ Correspondence should be addressed to Xueyi Zhang; zhangxueyi@sdut.edu.cn \\ Received 7 January 2019; Accepted 12 March 2019; Published 2 May 2019 \\ Academic Editor: Gorazd Stumberger \\ Copyright (c) 2019 Shilun Ma et al. This is an open access article distributed under the Creative Commons Attribution License, \\ which permits unrestricted use, distribution, and reproduction in any medium, provided the original work is properly cited. \\ Aiming at the disadvantages of large leakage flux and low magnetic flux density of radial magnetic circuit and tangential magnetic \\ circuit, a new type of permanent magnet (PM) rotor with parallel tangential and radial magnetic circuits is proposed. Based on \\ Ohm's law and Kirchhoff's law of magnetic circuits, equivalent magnetic circuits for rotor poles are developed. The structure \\ parameters of the generator are preliminarily determined. At the same time, by means of the Taguchi method and employing finite \\ element analysis, the rotor poles of generator are optimized to improve air gap magnetic density, the cogging torque, and the \\ distortion of back-EMF waveform. Finally, the validity of proposed design methods is validated by the analytical and \\ experimental results.
}

\section{Introduction}

Electric vehicles have been widely used in people's daily life due to their advantages of low pollution, low noise, and zero emission. But, the limited range has become a bottleneck restricting its development. Before electric vehicle battery storage technology made a major breakthrough, adding an extended-range generator for electric vehicles was one of the important ways to increase the endurance mileage $[1,2]$. So, the generator device is the key component of the power supply system of electric vehicles. With the perfection of the electric automobile, the power consumption is increasing and the silicon-rectifying generator has been unable to meet the demand of electrical equipment for power consumption. However, the permanent magnet generator is excited by PM, without electric excitation winding, and has the advantages of simple structure, high power density, high reliability, and so on, so it has a broad market prospect in the power supply system of electric vehicles $[3,4]$.

The literature [5] has proposed a novel surface-mounted and interior double radial PM synchronous generator, through the equivalent magnetic circuit (EMC) method. The magnetic permeance and magnetic leakage permeance of the generator are analyzed, and the optimal structural parameters of the generator are determined. One study [6] showed that using the level set method to optimize the PM synchronous generator, the cogging torque of the generator is reduced and the performance of the motor is improved. The literature [7] has proposed an axial magnetic circuit generator in which rotor pole is composed of core and PM and by optimizing the shape of the magnetic pole, harmonic content is reduced. The literature [8] presented a new type of rotor structure, in which main magnetic flux and leakage flux of the PM are calculated by the EMC method, the iteration does not converge when iron core is severely saturated. The literature [9] has established the open-circuit EMC model of the surface-mounted and interior synchronous PM motor and the EMC model under the armature reaction. The air gap magnetic field and the armature back EMF of the motor are solved; the accuracy of the analytical calculation is verified by the finite element results. The literature [10] makes use of genetic algorithm and particle swarm optimization to improve the comprehensive performance of the motor, but establishment and solution analysis of objective function in these algorithms are quite complex, which not only makes it difficult to realize the fast 
calculation of the optimal parameters but also has certain localization in the multiobjective optimization design. However, the Taguchi method is a local optimization algorithm which can realize the multiobjective optimization design of a generator. It not only can realize the rapid design of the generator but also has high design precision. It has been widely used in the field of generator development and design in recent years $[11,12]$.

In order to accurately design and analyze the relationship between the output characteristics of the tangential and radial parallel magnetic circuit permanent magnet generator (ITQPMG), the parameters of magnetic pole are determined. By establishing the model of EMC, the parameters of magnetic pole are preliminarily determined, and then, they are optimized by the Taguchi method. In this study, the parameters of magnetic pole have been selected as the horizontal variables. The multiobjective optimization of output characteristics such as the peak value of air gap magnetic density, waveform distortion rate of no-load back EMF, and the peak value of cogging torque is realized, so the optimal parameters combination can be obtained to improve the performance of ITQPMG.

\section{Determination of Main Parameters}

The magnetic circuit of the conventional PM generator is divided into radial directions and tangential directions. Although the generator of radial magnetic circuit has less leakage and back-EMF waveform has good sinusoidal property, the peak value of air gap flux density is lower. The interior radial permanent magnet generator (IRPMG) is shown in Figure 1(a); when the leakage of tangential magnetic circuit generator is large, tangential magnetic poles can produce a certain degree of magnet congregate effect. So the peak value of air gap density is high and the distortion rate of back-EMF waveform is low [13]. The interior tangential permanent magnet generator (ITPMG) is shown in Figure 1(b). In this study, the advantages of two kinds of PM generator of magnetic circuit are discussed and a new type of PM generator is proposed, which reduces the magnetism leakage between magnetic poles and tends back-EMF waveforms to be sinusoidal. The radial and tangential flux together provides the flux and synthesizes it in air gap, which has remarkable magnetic concentration effect, makes up the depression of back-EMF waveforms, and improves the efficiency of the generator. The structure of ITQPMG is shown in Figure 1(c). Initial design parameters are listed in Table 1.

\section{Establishment and Analysis of EMC Model}

According to the PM layout form and the characteristics of rotor topological structure, the EMC model is established under the no-load condition of the generator. The model consists of two independent flux paths: the first magnetic flux path is a closed magnetic path independently formed by tangential PM and the second flux paths are closed magnetic circuits formed by two series radial rectangle PM connections. The main flux path and leakage flux path of the new type structure of PM generator are shown in Figure 2, and the equivalent magnetic circuit of the ITQPMG is shown in Figure 3.

When the generator is working in no-load state, the direct axis component of armature reaction is $F_{d}=0$. According to Ohm's law and Kirchhoff's law of magnetic circuits, we can establish the EMC model as follows:

$$
\begin{aligned}
& \phi_{\mathrm{mT}}-\phi_{\mathrm{Tl}}=\frac{H_{\mathrm{c}} b_{\mathrm{mT}}}{\left(\left(G_{\mathrm{mT}} \cdot G_{\mathrm{Tl}}\right) /\left(G_{\mathrm{mT}}+G_{\mathrm{Tl}}\right)\right)+2\left(\left(1 / G_{\mathrm{r} 1}\right)+\left(1 / G_{\mathrm{g}}\right)+\left(1 / G_{\mathrm{ts}}\right)+\left(1 / G_{\mathrm{t}}\right)\right)+\left(1 / G_{\mathrm{y}}\right)}, \\
& \phi_{\mathrm{mQ}}-\phi_{\mathrm{Ql}}=\frac{2 H_{\mathrm{c}} b_{\mathrm{mQ}}}{\left(\left(2 \cdot G_{\mathrm{mQ}} \cdot G_{\mathrm{Ql}}\right) /\left(G_{\mathrm{mQ}}+G_{\mathrm{Ql}}\right)\right)+4\left(\left(1 / G_{\mathrm{r} 1}\right)+\left(1 / G_{\mathrm{g}}\right)+\left(1 / G_{\mathrm{ts}}\right)+\left(1 / G_{\mathrm{t}}\right)\right)+\left(1 / G_{\mathrm{y}}\right)+\left(1 / G_{\mathrm{r} 2}\right)},
\end{aligned}
$$

where $F_{\mathrm{mT}}$ is the equivalent magnetomotive force of tangential PM steel, $H_{\mathrm{c}}$ is the coercivity of $\mathrm{PM}, b_{\mathrm{mT}}$ is the thickness of tangential PM steel in the magnetization direction, $F_{\mathrm{mQ}}$ is the equivalent magnetomotive force of radial $\mathrm{PM}$ steel, $F_{d}$ is $d$ axis component of the armature reaction, $G_{\mathrm{mT}}$ is the permeance of tangential PM steel, $G_{\mathrm{mQ}}$ is the permeance of radial PM steel, $G_{\mathrm{Tl}}$ is the leakage permeance of tangential PM steel, $G_{\mathrm{Ql}}$ is the leakage permeance of radial PM steel, $G_{\mathrm{r} 1}$ is the permeance between rotor core and air gap, $G_{\mathrm{r} 2}$ is the permeance of rotor core between two radial PM steels, $G_{\mathrm{g}}$ is the permeance of air gap between rotor and stator, $G_{\mathrm{t}}$ is the permeance of stator tooth, $G_{\mathrm{ts}}$ is the permeance of stator boot, $G_{y}$ is the permeance of stator yoke, $\varphi_{\mathrm{mT}}$ is the flux provided by tangential PM steel, $\varphi_{\mathrm{mQ}}$ is the flux provided by radial PM steel, $\varphi_{\mathrm{Ql}}$ is the leakage flux of radial PM steel, $\varphi_{\mathrm{Tl}}$ is the leakage flux of radial PM steel, and $\varphi_{\mathrm{U}}$ is the effective flux.
The calculation formula of the phase's back EMF of generator:

$$
E=N \frac{d \phi_{\mathrm{U}}}{d_{\mathrm{t}}}=4.44 f N K_{\mathrm{w}} K_{\varphi}\left(\phi_{\mathrm{mT}}-\phi_{\mathrm{Tl}}+\phi_{\mathrm{mQ}}-\phi_{\mathrm{Ql}}\right),
$$

where $f$ is the frequency of the generator; $K_{\mathrm{w}}$ is the winding coefficient of the armature winding; $K_{\mathrm{w}}=K_{\mathrm{d}} \cdot K_{\mathrm{p}} \cdot K_{\mathrm{s}}$, where $K_{\mathrm{d}}$ is the distribution factor; $K_{\mathrm{d}}=\left(\sin \left[180^{\circ} /(2 m)\right]\right) /$ $\left(q \sin \left[180^{\circ} /(2 m q)\right]\right)$, where $q$ is the number of slots per pole of each phase; $q=\left(Z_{\mathrm{s}} / 2 \mathrm{pm}\right)$, where $Z_{\mathrm{s}}$ is the number of stator slots and $m$ is the number of phases, $m=3$; $K_{\mathrm{p}}$ is the short range factor; $K_{q}=\sin (180 \beta / 2), \beta=(y / m q)$, where $y$ is the pitch of winding; $K_{\varphi}$ is the waveform coefficient of air gap flux, $K_{\varphi}=1.11$; and $N$ is the armature winding turns of each phase.

The air gap circumferential flux produced by PM steel in rotor can be expressed in the following calculation formula: 


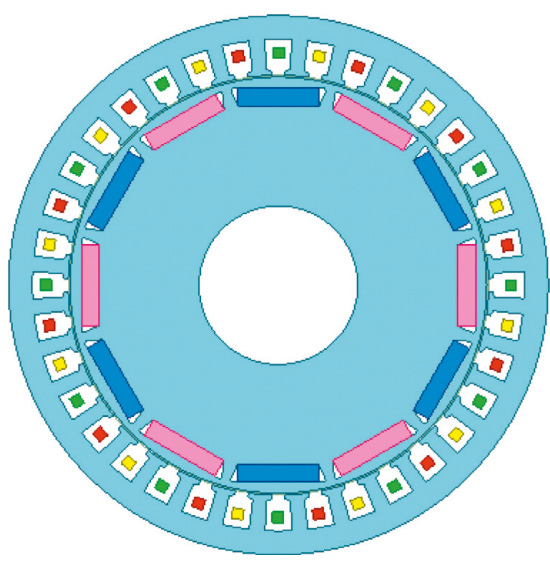

(a)

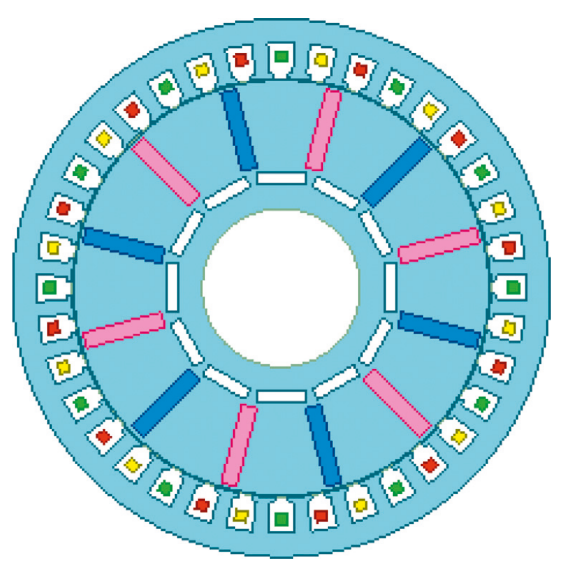

(b)

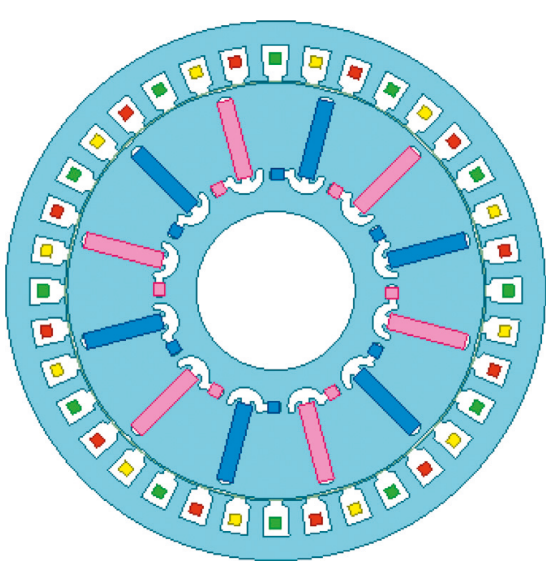

(c)

FIgURE 1: Structure of ITQPMG. (a) IRPMG. (b) ITPMG. (c) ITQPMG.

TABLE 1: Initial design parameters of the generator.

\begin{tabular}{lc}
\hline Parameters & Values \\
\hline Stator inner diameter $(\mathrm{mm})$ & 106 \\
Stator outer diameter $(\mathrm{mm})$ & 135 \\
Axial length $(\mathrm{mm})$ & 30 \\
Air gap length $(\mathrm{mm})$ & 0.5 \\
Number of stator slots & 36 \\
Rated power $(\mathrm{W})$ & 500 \\
Rated voltage $(\mathrm{V})$ & 28 \\
Rated speed $(\mathrm{r} / \mathrm{min})$ & 4000 \\
Pole pairs & 6 \\
Winding turns per slot & 11 \\
\hline
\end{tabular}

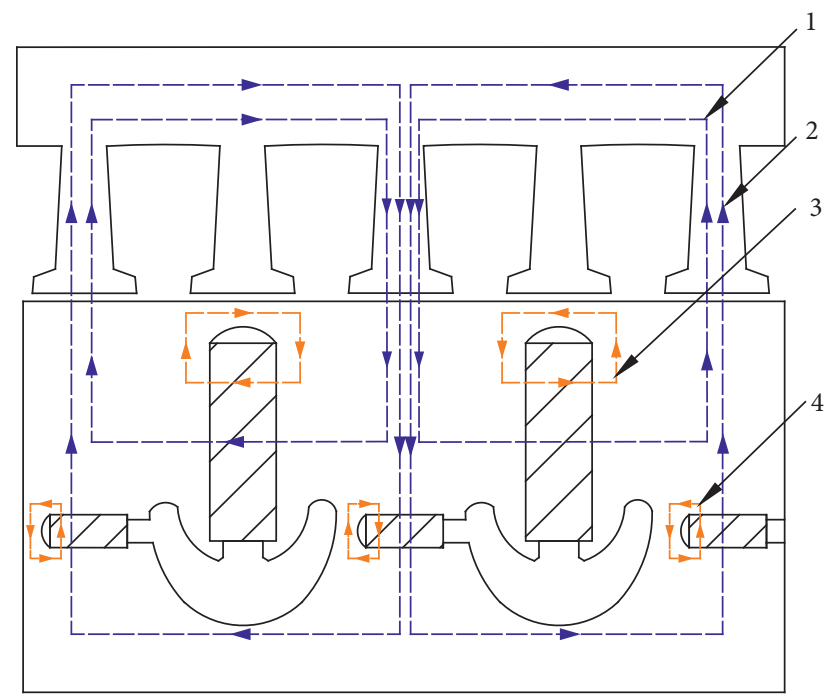

FIgUre 2: Diagram of magnetic flux of ITQPMG. (1) The main magnetic flux of tangential PM steel. (2) The main magnetic flux of radial PM steel. (3) The leakage flux of tangential PM steel. (4) The leakage flux of tangential PM steel.

$$
\phi_{\mathrm{U}}=\phi_{\mathrm{mT}}+\phi_{\mathrm{Tl}}+\phi_{\mathrm{mQ}}+\phi_{\mathrm{Ql}}=\pi D \alpha_{\mathrm{j}} \alpha_{\mathrm{m}} B_{\mathrm{r}} L \times 10^{-4}
$$

where $D$ is the rotor diameter, $\alpha_{\mathrm{j}}$ is the mechanical pole arc coefficient of the generator, $\alpha_{\mathrm{m}}$ is the magnetic pole arc coefficient, $B_{\mathrm{r}}$ is the remanent flux density, and $L$ is the generator's axial length.

The wye connection method is used in this design, so the no-load back EMF is equal to $\sqrt{3}$ times the rated voltage. Therefore, the width of the tangential PM steel is $11 \mathrm{~mm}$, the thickness of the magnetization direction is $4 \mathrm{~mm}$, the width of the radial PM steel is $6 \mathrm{~mm}$, the thickness of the magnetization direction is $2 \mathrm{~mm}$, and the implanting depth of the radial $\mathrm{PM}$ is $14 \mathrm{~mm}$.

\section{Optimal Design of Rotor Pole}

The size and position of the rotor pole have a significant influence on the performance of the PM generator. However, the parameters of magnetic pole calculated by the EMC method may not be the best performance parameter, so it is necessary to optimize the design of the rotor pole. The Taguchi method is a local optimization algorithm, which can optimize multiple objectives at the same time. By establishing the orthogonal test table, the optimal combination of multiobjective optimization design parameters can be calculated with the least experiment times. In this study, the Taguchi method is used to optimize the rotor poles of ITQPMG.

4.1. Test Schemes. For PM generator with parallel magnetic circuit, the parameters of PM and implanting radial depth of PM have great influence on the performance [14]. Therefore, there are three optimization objectives in this study, such as the peak value of the cogging torque $(T)$, the peak value of the air gap flux density $(G)$, and the distortion rate of the noload back EMF $\left(K_{\mathrm{r}}\right)$. The width of tangential PM $\left(h_{\mathrm{mT}}\right)$, the thickness of the magnetization direction of the tangential PM $\left(b_{\mathrm{mT}}\right)$, the width of the radial PM $\left(h_{\mathrm{mQ}}\right)$, the thickness of the magnetization direction of the radial PM $\left(b_{\mathrm{mQ}}\right)$, and the implanting depth of the radial PM $(b)$ are selected as variables. The experimental matrix and finite element results are shown in Table 2. 


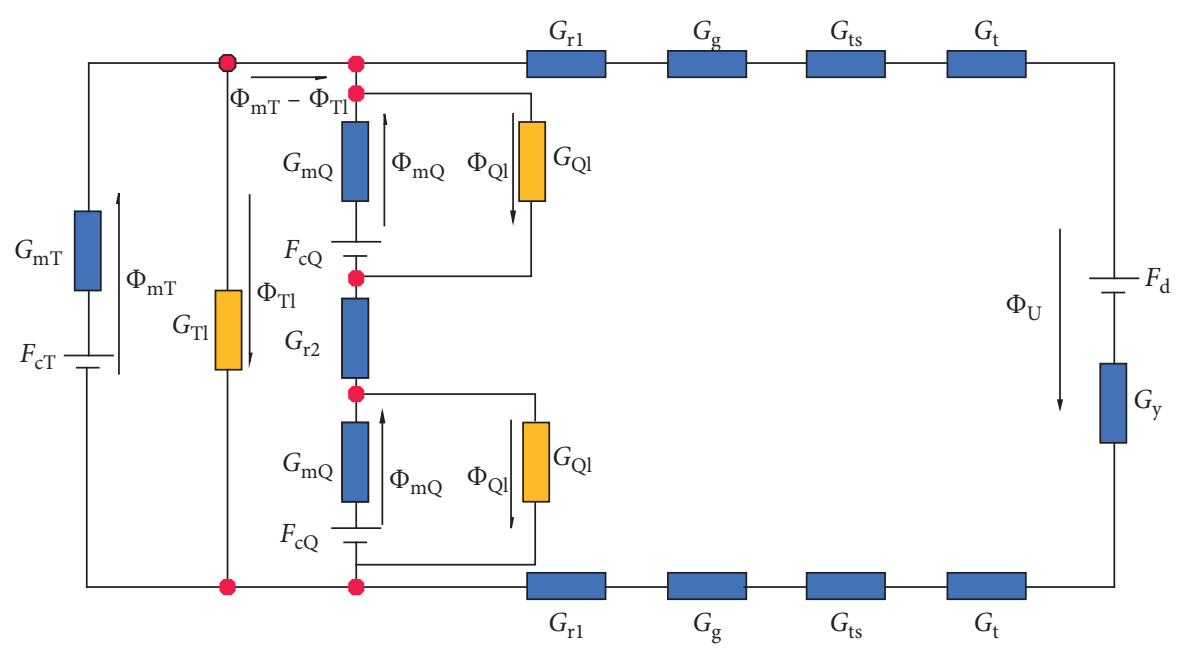

FIgURE 3: EMC diagram of the ITQPMG.

TABLE 2: Test table of optimization parameters and factor level.

\begin{tabular}{lccccc}
\hline Parameters & $\begin{array}{c}h_{\mathrm{mT}} \\
(\mathrm{mm})\end{array}$ & $\begin{array}{c}b_{\mathrm{mT}} \\
(\mathrm{mm})\end{array}$ & $\begin{array}{c}h_{\mathrm{mQ}} \\
(\mathrm{mm})\end{array}$ & $\begin{array}{c}b_{\mathrm{mQ}} \\
(\mathrm{mm})\end{array}$ & $\begin{array}{c}b \\
(\mathrm{~mm})\end{array}$ \\
\hline Factor level 1 & 10 & 2 & 4 & 2 & 10 \\
Factor level 2 & 11 & 3 & 5 & 3 & 12 \\
Factor level 3 & 12 & 4 & 6 & 4 & 14 \\
Factor level 4 & 13 & 5 & 7 & 5 & 16 \\
\hline
\end{tabular}

The calculation formula of back-EMF waveform distortion rate for PM generator [15-17]:

$$
K_{\mathrm{r}}=\frac{\sqrt{U_{2}^{2}+U_{3}^{2}+U_{4}^{2}+\cdots+U_{N}^{2}}}{U_{1}} \times 100 \%,
$$

where $U_{N}$ is the amplitude of $N$ th harmonics.

According to the factors and levels in Table 2, the experimental matrix of $L 16\left(4^{5}\right)$ is established. If the traditional single-variable and single-objective optimization method uses $4^{5}=1024$ experiments, the optimization design of the multiparameter and multitarget of permanent magnet generator can be completed by the Taguchi method only with 16 experiments. The orthogonal experimental matrix of influencing factors is established, and the experimental results are solved with finite element analysis software. The results of the experimental orthogonal table and the simulation solution are shown in Table 3.

According to the formula, the average value of the solution in Table 3 is calculated:

$$
M(S)=\frac{1}{n} \sum_{i}^{n} S_{i}=\frac{1}{16} \sum_{i=1}^{16} S(i),
$$

where $n$ is the experiment times and $S_{i}$ is the average value of the target performance of the $i$ th times.

The calculation results are shown in Table 4 .

Then, the average value of each factor level of the parameter to the specific target performance is calculated:

$$
M_{x i}=\frac{1}{4}\left[M_{x}(j)+M_{x}(k)+M_{x}(l)+M_{x}(n)\right],
$$

where $M_{x i}$ is the average value of the performance index under the $i$ th factor of parameter $x, M_{x}$ is the performance index of parameter $x$ under a certain experiment, and $J, k, l$, and $n$ are the serial numbers of the experiment.

In order to facilitate the comprehensive analysis, the change of the indicators with the level of factors is represented by broken lines, as shown in Figures 4-6.

From Figures 4-6, it is observed that these three sets of horizontal combinations are designed for optimization of single performance indices. For example, considering the effect of three performance indices on ITQPMG, it is necessary to analyze the variance to further analyze the influence of the changes of each parameter on the different performance indices and to determine the parameters. Changing the proportion of the influence on its performance indices and obtaining the optimization results, we obtain

$$
S(s)=\frac{1}{z} \sum_{i=1}^{z}\left[M_{x i}-M(s)\right]^{2},
$$

where $s$ is the influence of factors, such as $b_{1}, h_{1}, b_{2}, h_{2}$, and $b$; $S(s)$ is the variance of performance index under the parameter $s ; M(s)$ is the total average value of a performance index. The calculation results of variance reflect the proportion of different level factors to each test index. The result of $S(s)$ is shown in Table 5.

4.2. Determination of the Final Optimization Scheme. As can be seen from Table 5, the size of variance can directly reflect the proportion of the impact of optimization parameters on performance indicators $[18,19]$. The parameter $b_{\mathrm{mT}}$ has the greatest influence on the air gap magnetic density peak and the back-EMF waveform of the PM generator. Compared with the proportion of $S_{\mathrm{Kr}}$ and $S_{\mathrm{G}}$, the width of tangential PM steel $h_{\mathrm{mT}}$ has great influence on the cogging torque of the PM generator. The magnetization direction thickness of the radial $\mathrm{PM}$ steel $b_{\mathrm{mQ}}$ and the implanting depth of PM steel $b$ have the greatest influence on the peak value of air gap magnetic density. 
TABLE 3: Experimental matrix and finite element analysis.

\begin{tabular}{|c|c|c|c|c|c|c|c|c|}
\hline \multirow{2}{*}{ No. } & \multicolumn{5}{|c|}{ Experimental matrix } & \multirow[b]{2}{*}{$K_{\mathrm{r}}(\%)$} & \multirow[b]{2}{*}{$T(\mathrm{~N} \cdot \mathrm{m})$} & \multirow[b]{2}{*}{$G(\mathrm{~T})$} \\
\hline & $h_{\mathrm{mT}}(\mathrm{mm})$ & $b_{\mathrm{mT}}(\mathrm{mm})$ & $h_{\mathrm{mQ}}(\mathrm{mm})$ & $b_{\mathrm{mQ}}(\mathrm{mm})$ & $b(\mathrm{~mm})$ & & & \\
\hline 1 & 1 & 1 & 1 & 1 & 1 & 47.1 & 0.58 & 0.51 \\
\hline 2 & 1 & 2 & 2 & 2 & 2 & 40.2 & 0.81 & 0.63 \\
\hline 3 & 1 & 3 & 3 & 3 & 3 & 36.2 & 1.04 & 0.74 \\
\hline 4 & 1 & 4 & 4 & 4 & 4 & 31.4 & 1.32 & 0.83 \\
\hline 5 & 2 & 1 & 2 & 3 & 4 & 45.3 & 0.75 & 0.58 \\
\hline 6 & 2 & 2 & 1 & 4 & 3 & 41.8 & 0.85 & 0.62 \\
\hline 7 & 2 & 3 & 4 & 1 & 2 & 35.8 & 1.12 & 0.80 \\
\hline 8 & 2 & 4 & 3 & 2 & 1 & 31.4 & 1.29 & 0.82 \\
\hline 9 & 3 & 1 & 3 & 4 & 2 & 43.1 & 1.04 & 0.69 \\
\hline 10 & 3 & 2 & 4 & 3 & 1 & 39.3 & 1.37 & 0.79 \\
\hline 11 & 3 & 3 & 1 & 2 & 4 & 36.2 & 1.17 & 0.75 \\
\hline 12 & 3 & 4 & 2 & 1 & 3 & 30.5 & 1.16 & 0.81 \\
\hline 13 & 4 & 1 & 4 & 2 & 3 & 42.6 & 1.22 & 0.74 \\
\hline 14 & 4 & 2 & 3 & 1 & 4 & 40.4 & 1.46 & 0.80 \\
\hline 15 & 4 & 3 & 2 & 4 & 1 & 35.8 & 1.17 & 0.76 \\
\hline 16 & 4 & 4 & 1 & 3 & 2 & 31.4 & 1.33 & 0.84 \\
\hline
\end{tabular}

TABLe 4: Average value of performance index.

\begin{tabular}{lcccc}
\hline Optimization index & $K_{\mathrm{r}}(\%)$ & $T(\mathrm{~N} \cdot \mathrm{m})$ & $G(\mathrm{~T})$ \\
\hline$m$ & 38 & 1.105 & 0.73 \\
\hline
\end{tabular}

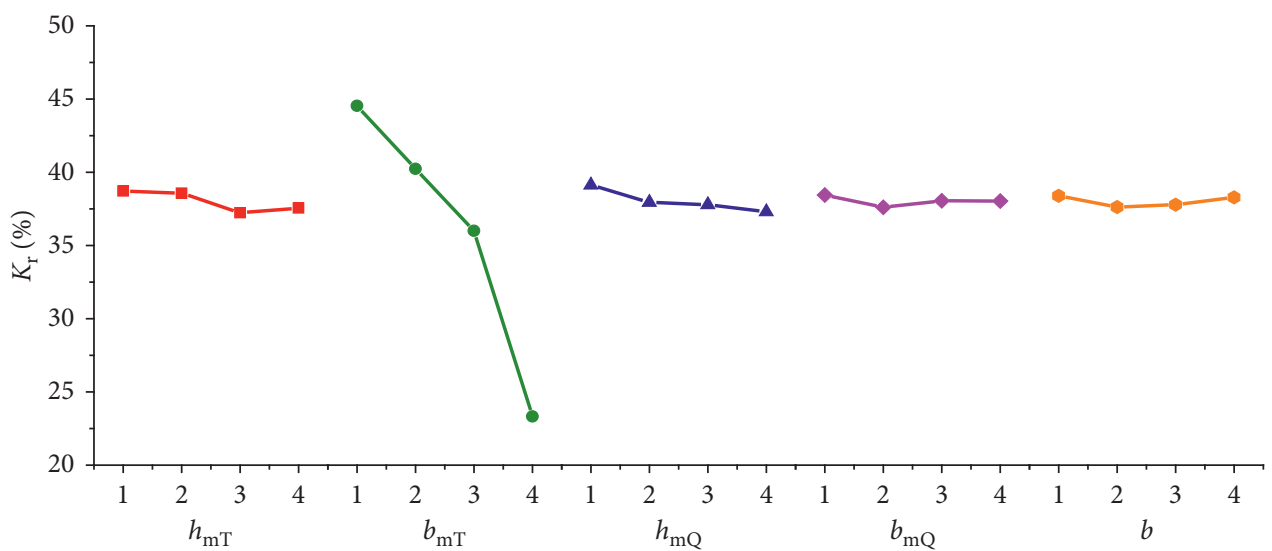

FIgURE 4: Impact of various factors on $K_{\mathrm{r}}$.

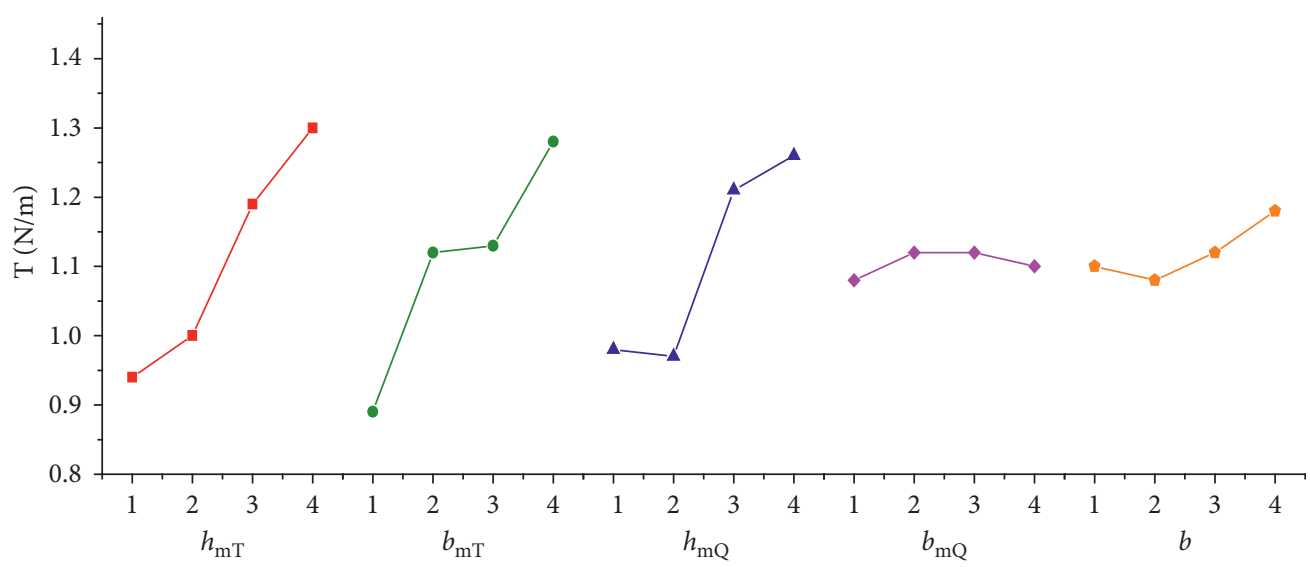

FIgURE 5: Impact of various factors on $T$. 


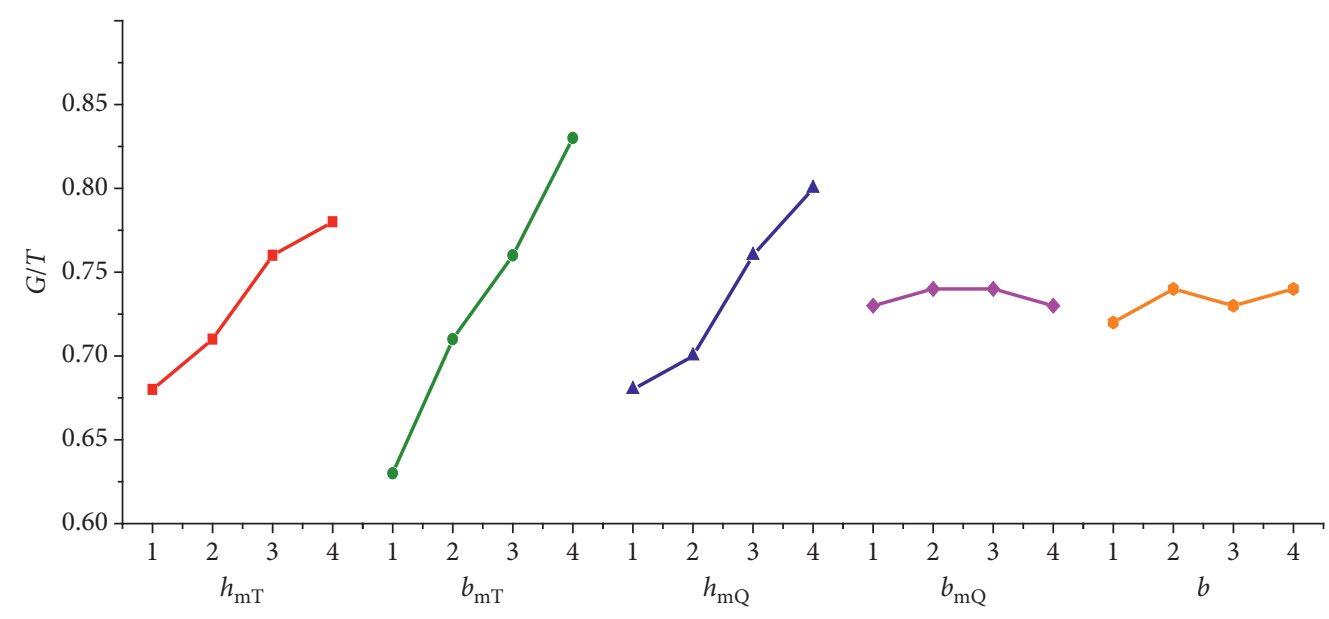

FIGURE 6: Impact of various factors on $G$.

TABLE 5: Variance and proportion of the performance indices of each parameter under 4 level factors.

\begin{tabular}{lcccccc}
\hline \multirow{2}{*}{ Parameters } & \multicolumn{2}{c}{$\mathrm{S}_{\mathrm{Kr}}$} & \multicolumn{2}{c}{$S_{\mathrm{T}}$} & \multicolumn{2}{c}{$S_{\mathrm{G}}$} \\
& Variance & Proportion (\%) & Variance & Proportion (\%) & Variance & Proportion (\%) \\
\hline$h_{\mathrm{mT}}$ & 0.396 & 0.85 & 0.0210 & 23.28 & 0.0016 & 16.50 \\
$b_{\mathrm{mT}}$ & 24.760 & 53.65 & 0.0180 & 19.96 & 0.0053 & 54.64 \\
$h_{\mathrm{mQ}}$ & 20.743 & 45.00 & 0.0490 & 54.32 & 0.0020 & 20.62 \\
$b_{\mathrm{mQ}}$ & 0.116 & 0.35 & 0.0003 & 2.11 & 0.00005 & 0.00075 \\
$b$ & 0.072 & 0.15 & 0.0019 & 100 & 0.00970 & 1.73 \\
Total & 46.087 & 100 & 0.0902 & & & 100 \\
\hline
\end{tabular}

According to the above analysis, the selection of all factors should be based on the optimization standard of the unloaded back EMF-waveform distortion rate, peak value of air gap magnetic density maximum, and peak value of cogging torque minimum. Finally, the parameter combination $\left[h_{\mathrm{mT}}(1) b_{\mathrm{mT}}\right.$ (4) $h_{\mathrm{mQ}}$ (1) $\left.b_{\mathrm{mQ}}(3) b(2)\right]$ is determined to be the best combination. The magnetization direction of tangential PM steel is $5 \mathrm{~mm}$, the width of radial rectangular PM steel is $4 \mathrm{~mm}$, the thickness of the magnetization direction of radial rectangular PM steel is $4 \mathrm{~mm}$, and the radial rectangular PM steel is implanted deep. The implanting depth of PM steel is $12 \mathrm{~mm}$.

\section{Result of Finite Element Analysis}

In order to verify the superiority of the optimized PM generator, the initial design structure calculated by the EMC method and the optimized structure parameters obtained by the Taguchi method are compared and analyzed. In the case of the same stator structure, winding mode, rotor diameter, silicon steel sheet, and PM material of the two PM generators mentioned above, both are compared and analyzed by the finite element method.

Figure 7 is the no-load back-EMF waveform of the two cycles before and after optimization. It can be seen that the peak value of the no-load back-EMF wave before optimization has obvious depression and the no-load back-EMF waveform of the optimized ITQPMG is closer to the sinusoidal wave. It is shown that the sinusoidal EMF waveform can be obtained by the optimized design.

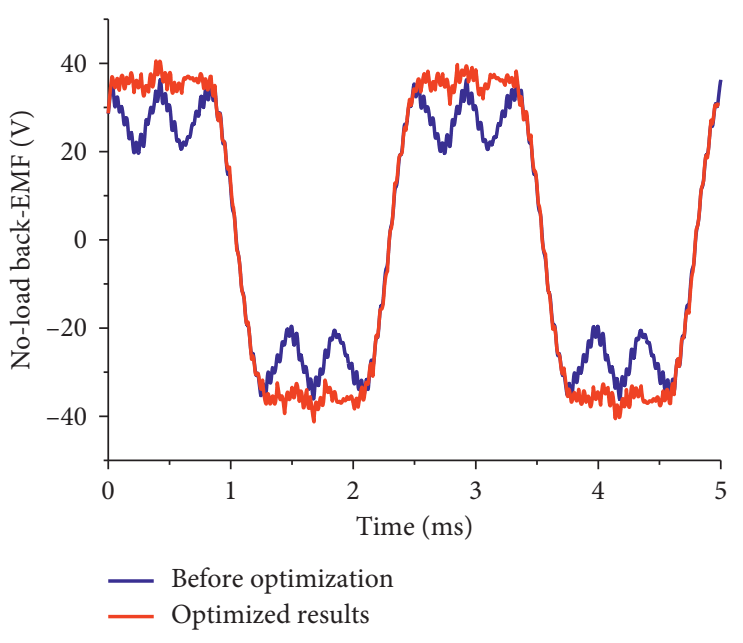

FIgURE 7: Comparison results of back-EMF waveforms.

Figure 8 shows the amplitude of each harmonic content in the no-load back EMF before and after the optimization. It can be seen that the amplitude of the fundamental wave before optimization is $36.77 \mathrm{~V}$, the waveform distortion rate is $45 \%$, the amplitude of the fundamental wave after optimization is $38.63 \mathrm{~V}$, and the waveform distortion rate is $33 \%$.

Figure 9 shows the cogging torque before and after the optimization of the generator. It can be seen that the optimized cogging torque decreases from $1.12 \mathrm{~N} \cdot \mathrm{m}$ to $0.55 \mathrm{~N} \cdot \mathrm{m}$ after optimization, which is reduced by about $51 \%$. 


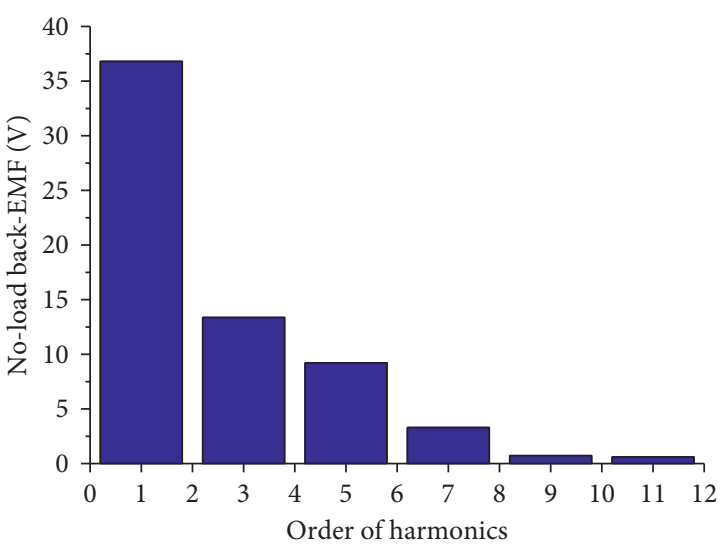

(a)

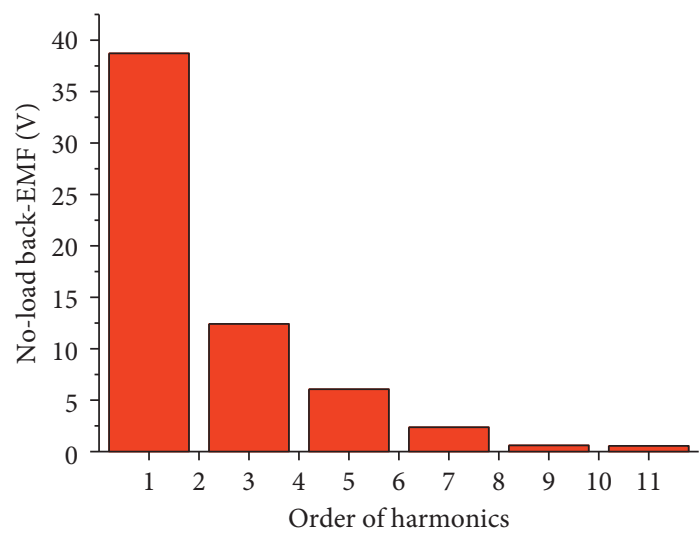

(b)

Figure 8: Comparison results of each harmonic content of no-load back EMF. (a) The amplitude of harmonics before optimization. (b) The amplitude of harmonics after optimization.

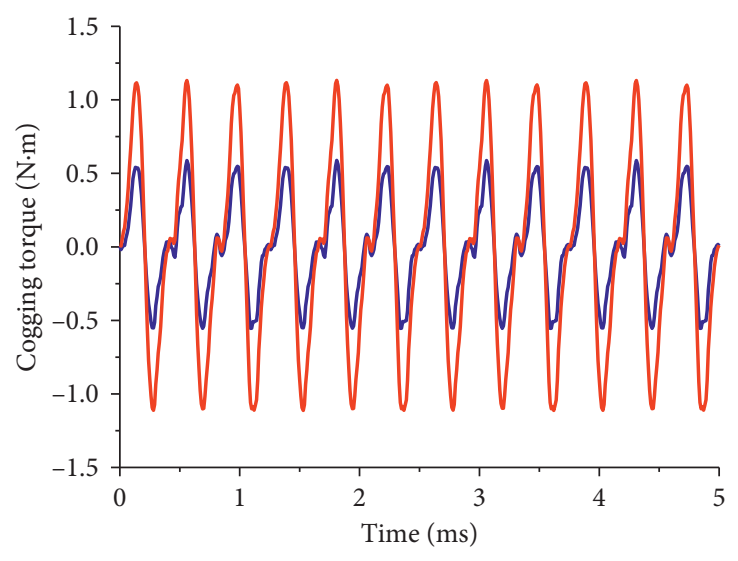

- Before optimization

- Optimized results

FIgURE 9: Comparison results of cogging torque.

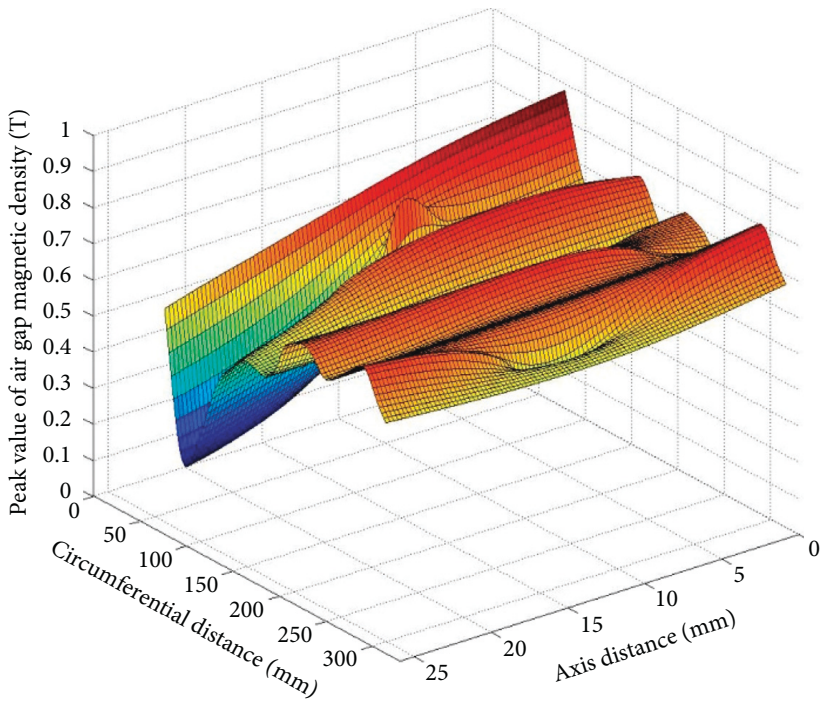

(a)

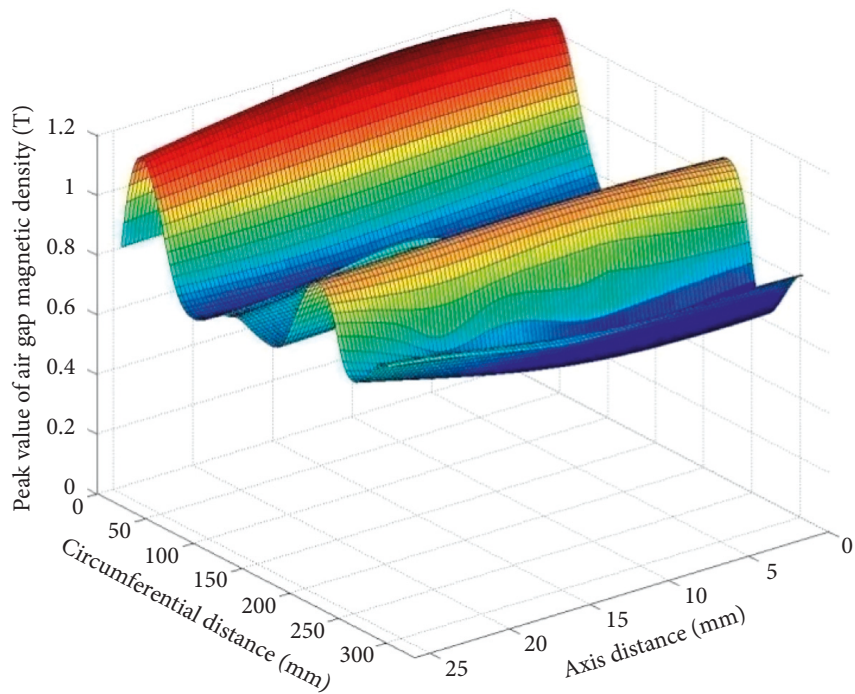

(b)

FIGURE 10: Comparison results of peak value of air gap magnetic density. (a) The peak value of air gap magnetic density before optimization. (b) The peak value of air gap magnetic density after optimization. 


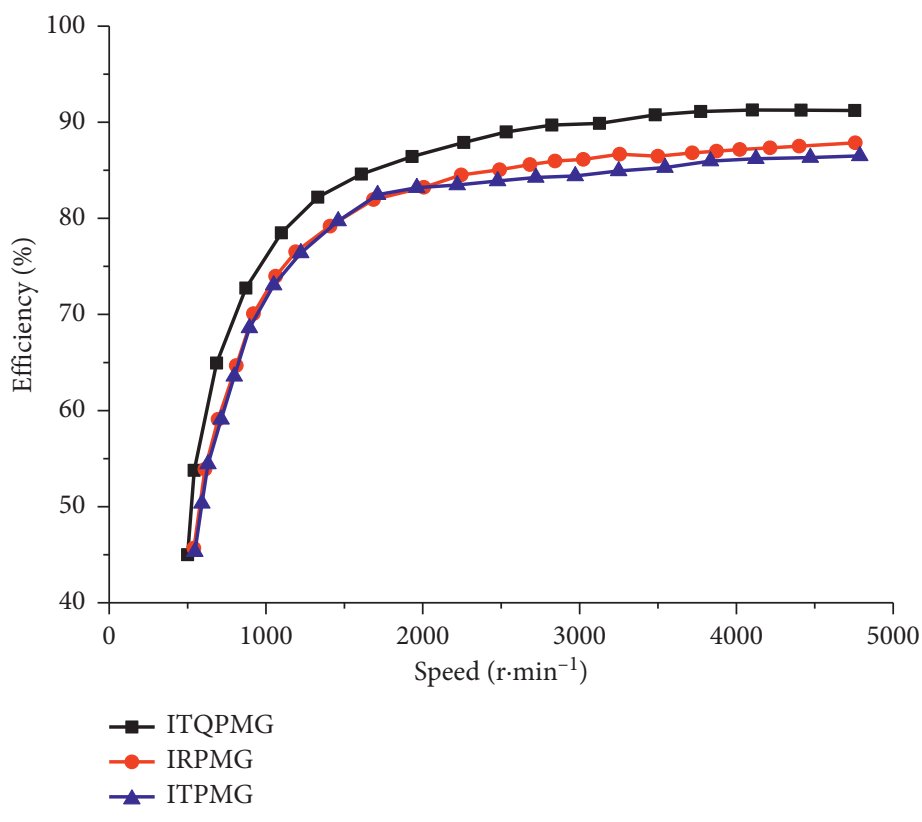

FIGURE 11: Efficiency curves of three permanent magnet generators.

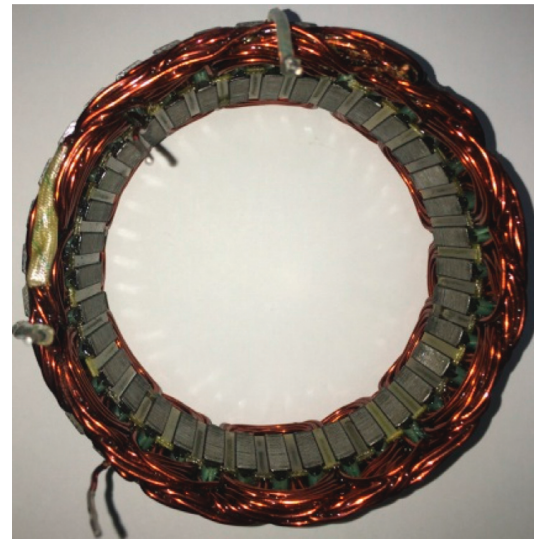

(a)

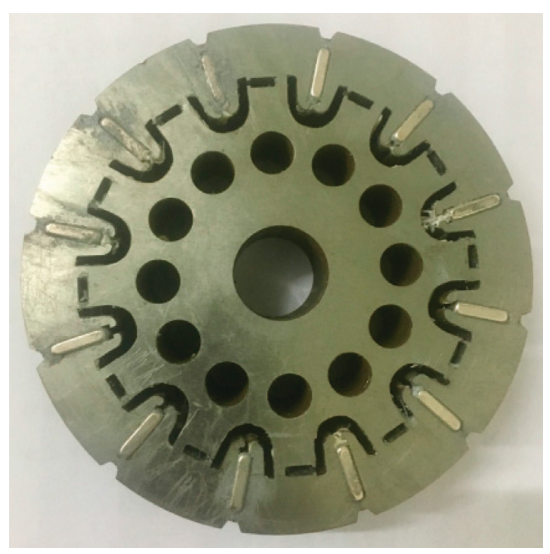

(b)

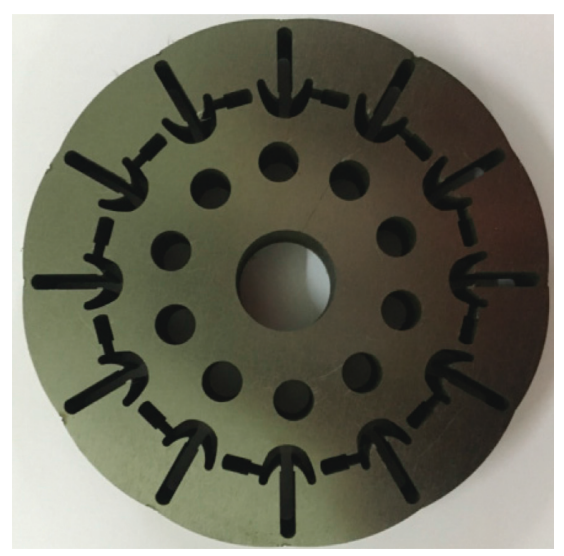

(c)

FIgURE 12: The photographs of ITQPMG. (a) The stator of ITQPMG. (b) The rotor before optimization. (c) Optimized rotor.
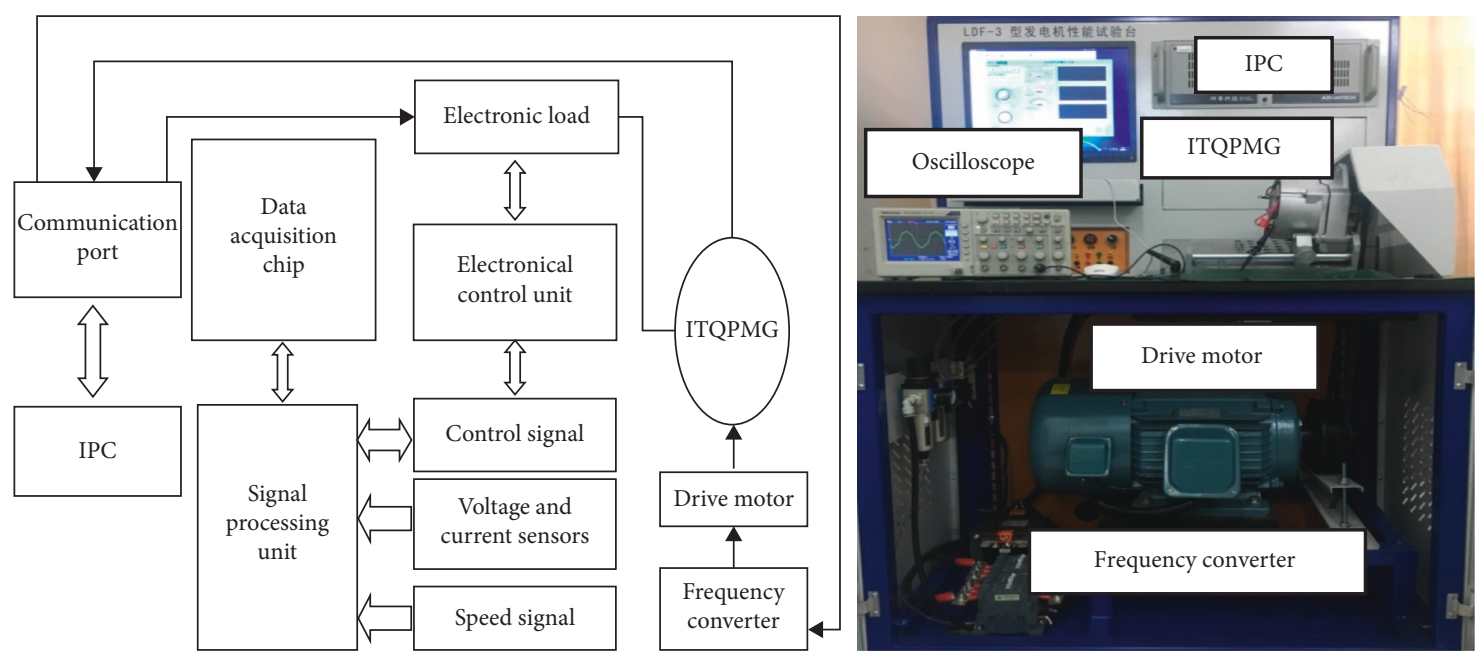

FIGURE 13: Generator performance test system and its principle block diagram. 


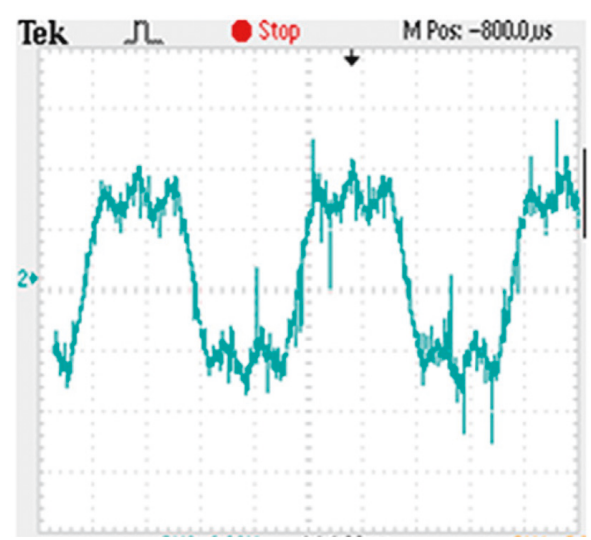

(a)

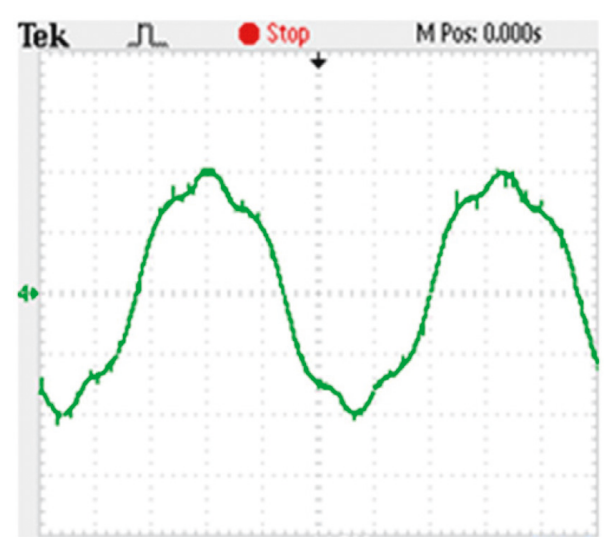

(b)

Figure 14: Comparison experimental results of no-load back-EMF waveforms. (a) No-load back-EMF waveforms before optimization. (b) No-load back-EMF waveforms after optimization.

Figure 10 shows the variation pattern of the peak value of air gap magnetic density along the axial and radial directions of the rotor before and after optimization. It can be seen that the peak value of air gap magnetic density before optimization is $0.83 \mathrm{~T}$ and it appeared at the position of $12 \mathrm{~mm}$ in the axial direction and $94 \mathrm{~mm}$ in the radial direction, while the optimized peak value of air gap magnetic density is $1.12 \mathrm{~T}$, it appears at the position of $5 \mathrm{~mm}$ axial distance and $27 \mathrm{~mm}$ circumferential distance. Compared to the optimization, the peak value of air gap magnetic density has been improved by about $35 \%$.

In order to verify the advantages of the ITQPMG, it is compared with the efficiency of two other traditional PM generators, as shown in Figure 11. With the increase of speed, the efficiency of ITQPMG is higher than that of the other two traditional PM generators. The maximum efficiency of ITPMG is $86.5 \%$, and the maximum efficiency of IRPMG is $88.6 \%$, while the maximum efficiency of ITQPMG can reach 91.2\%. This is because ITQPMG not only has less magnetic leakage but also has significant magnet congregate effect.

\section{Performance Test}

The photographs are shown in Figure 12, and the generator test system and its principle block are shown in Figure 13. The working process of the generator test system is mainly controlled by IPC to control the speed of frequency motor, so as to change the speed of ITQPMG and electronic load for testing. Data acquisition chip and signal processing unit are used to collect and analyze the signals of voltage, current, and speed. Then, the test data are fed back to the electrical control unit to complete the automatic adjustment of the electronic load, thus completing the performance test of the generator.

The experimental platform is driven by a $11 \mathrm{~kW}$ variable frequency motor as the drive motor to operate the generator, and the no-load and load experiments are carried out, respectively.

When the ITQPMG prototype is running at the rated speed of $4000 \mathrm{r} / \mathrm{min}$, the no-load back-EMF waveform before and after optimization is shown in Figure 14. It can be seen that the optimized no-load back-EMF waveform is
TABLE 6: Test results of the generator output voltage.

\begin{tabular}{lcc}
\hline Speed $(\mathrm{r} / \mathrm{min})$ & Load power $(\mathrm{W})$ & Output voltage $(\mathrm{V})$ \\
\hline \multirow{2}{*}{2000} & 480 & 26.8 \\
& 500 & 26.6 \\
& 520 & 26.2 \\
\multirow{3}{*}{4000} & 480 & 28.3 \\
& 500 & 28.4 \\
& 520 & 28.3 \\
\hline \multirow{2}{*}{4800} & 480 & 28.6 \\
& 500 & 28.6 \\
\hline
\end{tabular}

closer to the sine wave, the peak value of the no-load backEMF is increased, and the distortion rate of the waveform is reduced. The experimental test is basically consistent with the result of the finite element analysis method.

Finally, in the case of load power of $480 \mathrm{~W}, 500 \mathrm{~W}$, and $520 \mathrm{~W}$, the load performance test of the optimized ITQPMG is carried out and the experimental results are shown in Table 6.

It is found from Table 6 that the output voltage maintains around $26.2 \mathrm{~V} 28.6 \mathrm{~V}$ for the generator speed of $2000 \mathrm{r} /$ $\mathrm{min} \sim 4800 \mathrm{r} / \mathrm{min}$ and load power of $480 \mathrm{~W} \sim 520 \mathrm{~W}$, which meets the design requirements.

\section{Conclusion}

A new type of rotor topology of PM generator with tangential magnetic circuit and radial magnetic circuit which provide a common air gap magnetic field is developed. This structure has less magnetic flux, lower cogging torque, and significant magnetic congregate effect.

The structural parameters of the PM generator are preliminarily determined by the analytical calculation of the EMC method, and the Taguchi method is introduced to optimize the multiobjective design of the tangential and radial parallel magnetic circuits of the PM generator. The optimum combination of ITQPMG is obtained. Combined with the finite element method, the optimization results are compared and analyzed. The cogging torque is reduced by $51 \%$, the air gap magnetic density is increased 
by $35 \%$, the peak value of no-load back-EMF waveform is reduced by $12 \%$, and the waveform is closer to the sine.

The performance test is performed with various rotary speeds and load powers. When the generator speed changes from $2000 \mathrm{r} / \mathrm{min} \sim 4800 \mathrm{r} / \mathrm{min}$ and the load power varies from $480 \mathrm{~W} \sim 520 \mathrm{~W}$, the output voltage maintains around $26.2 \mathrm{~V} \sim 28.6 \mathrm{~V}$, which has an excellent regulator performance.

\section{Data Availability}

The data used to support the findings of this study are included within the article.

\section{Conflicts of Interest}

The authors declare that they have no conflicts of interest.

\section{Authors' Contributions}

M. S. built the equivalent magnetic circuit model and wrote most of the paper. X. Z. proposed the new type of motor structure. Q. D. analyzed the finite element simulation analysis of the generator. L. S. optimized the parameters of magnetic pole of the generator. X. M. was in charge of analysis of equations and drawing some charts.

\section{Acknowledgments}

This work was supported by grants from the National Natural Science Foundation of China (Project no. 51875327) and the Natural Science Foundation of Shandong Province (Project nos. ZR2018LE010 and ZR2017MF045).

\section{References}

[1] X. Zhang, L. Shi, and Y. Wang, "Design and stabilivolt analysis of Nd-Fe-B permanent magnet generator for electric vehicle range extender," International Journal of Electric and Hybrid Vehicles, vol. 3, no. 3, pp. 259-271, 2011.

[2] Q. Du, S. Ma, W. Hu, H. Geng, and X. Zhang, "Magnetic flux analysis and performance test of permanent magnet and clawpole electromagnetic hybrid excitation generator for electric vehicle range extender," International Journal of Electric and Hybrid Vehicles, vol. 9, no. 3, p. 187, 2017.

[3] L. Shi, B. Yan, X. Zhou, and X. Zhang, "Open-circuit faulttolerant characteristics of a new four-phase doubly salient electro-magnetic generator," Sustainability, vol. 10, no. 11, p. 4136, 2018.

[4] X. Zhang, Q. Du, C. Ma et al., "Nd-Fe-B permanent magnet generator and voltage stabilizing control technology for vehicles," Advances in Mechanical Engineering, vol. 8, no. 9, article 168781401666963, 2016.

[5] X. Zhang, Q. Du, S. Ma et al., "Permeance analysis and calculation of the double-radial rare-earth permanent magnet voltage-stabilizing generation device," IEEE Access, vol. 6, pp. 23939-23947, 2018.

[6] S. Lim, S. Min, and J.-P. Hong, "Level-set-based optimal stator design of interior permanent-magnet motor for torque ripple reduction using phase-field model," IEEE Transactions on Magnetics, vol. 47, no. 10, pp. 3020-3023, 2011.
[7] H. Wang, Z. Qu, S. Tang, M. Pang, and M. Zhang, "Analysis and optimization of hybrid excitation permanent magnet synchronous generator for stand-alone power system," Journal of Magnetism and Magnetic Materials, vol. 436, pp. 117-125, 2017.

[8] G. Xu, G. Liu, S. Jiang, and Q. Chen, "Analysis of a hybrid rotor permanent magnet motor based on equivalent magnetic network," IEEE Transactions on Magnetics, vol. 54, no. 4, pp. 1-9, 2018.

[9] S. I. Ji-Kai, H. E. Song, H. C. Feng et al., "Characteristic analysis of surface-mounted and interior hybrid permanent magnet synchronous motor based on equivalent magnetic circuit method," Journal of China Coal Society, vol. 40, no. 5, pp. 1199-1205, 2015.

[10] A. Mahmoudi, S. Kahourzade, N. A. Rahim, and W. P. Hew, "Design, analysis, and prototyping of an axial-flux permanent magnet motor based on genetic algorithm and finite-element analysis," IEEE Transactions on Magnetics, vol. 49, no. 4, pp. 1479-1492, 2013.

[11] X. Jannot, J.-C. Vannier, C. Marchand, M. Gabsi, J. SaintMichel, and D. Sadarnac, "Multiphysic modeling of a highspeed interior permanent-magnet synchronous machine for a multiobjective optimal design," IEEE Transactions on Energy Conversion, vol. 26, no. 2, pp. 457-467, 2011.

[12] S. Lee, S. Cho, K. Kim, J. Jang, T. Lee, and J. Hong, "Optimal design of interior permanent magnet synchronous motor considering the manufacturing tolerances using Taguchi robust design," IET Electric Power Applications, vol. 8, no. 1, pp. 23-28, 2014.

[13] G. Hong and Q. Hao, "Robust design for reducing torque ripple in permanent magnet synchronous motor," Chinese Society of Electrical Engineering, vol. 32, no. 24, pp. 88-95, 2012.

[14] J. Du, X. Wang, and H. Lv, "Optimization of magnet shape based on efficiency map of IPMSM for EVs," IEEE Transactions on Applied Superconductivity, vol. 26, no. 7, pp. 1-7, 2016.

[15] M. Si, X. Yu Yang, S. Wei Zhao, and S. Gong, "Design and analysis of a novel spoke-type permanent magnet synchronous motor," IET Electric Power Applications, vol. 10, no. 6, pp. 571-580, 2016.

[16] Z. Lan, X. Yang, F. Wang et al., "Application for optimal designing of sinusoidal interior permanent magnet synchronous motors by using the Taguchi method," Journal of Electrical Engineer, vol. 26, no. 12, pp. 37-42, 2011.

[17] S. I. Kim, J. Y. Lee, Y. K. Kim et al., "Optimization for reduction of torque ripple in interior permanent magnet motor by using the Taguchi method," IEEE Transactions on Magnetics, vol. 41, no. 5, pp. 1796-1799, 2005.

[18] S. Jikai, L. Zhang, F. Haichao et al., "Multi-objective optimal design of a surface-mounted and interior permanent magnet synchronous motor," Journal of China Coal Society, vol. 41, no. 12 , pp. 3167-3173, 2016.

[19] C. Hwang, S. Hung, C. Liu et al., "Optimal design of a high speed SPM motor for machine tool applications," IEEE Transactions on Magnetics, vol. 50, no. 1, 2014. 


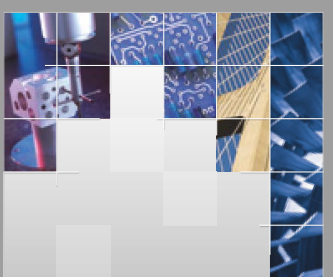

\section{Enfincering}
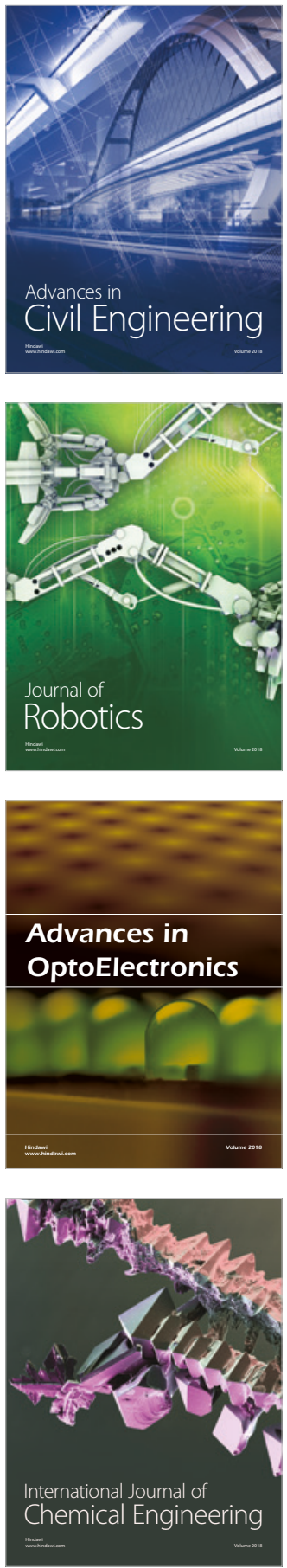

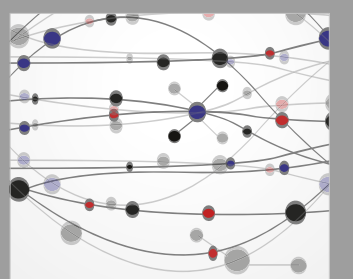

\section{Rotating \\ Machinery}

The Scientific World Journal

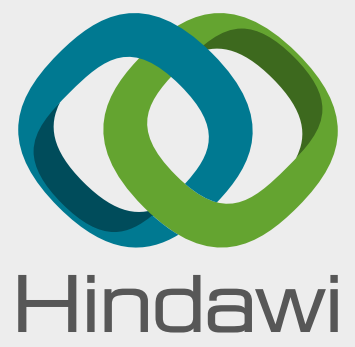

Submit your manuscripts at

www.hindawi.com
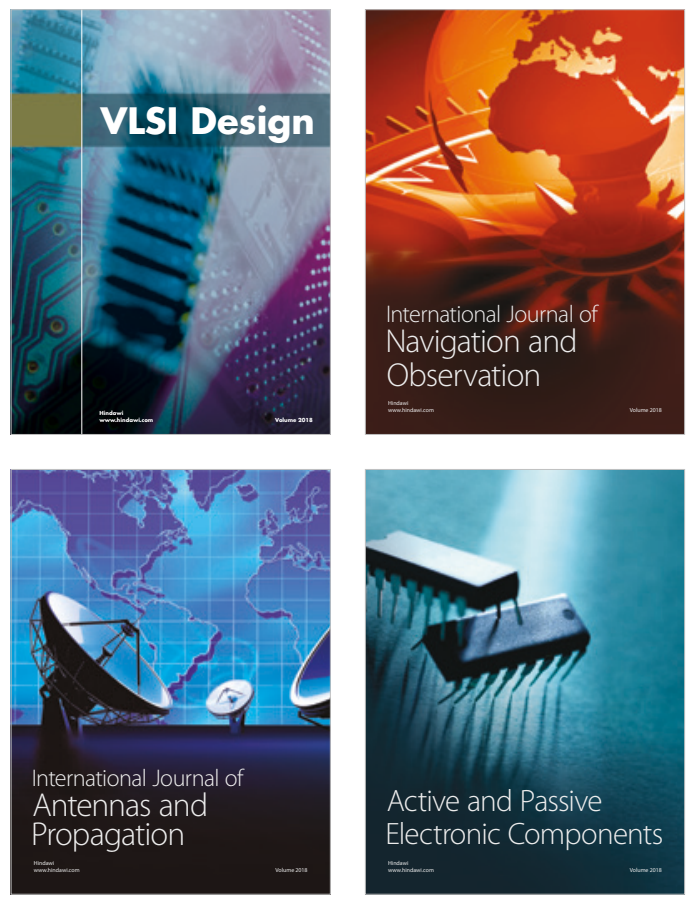
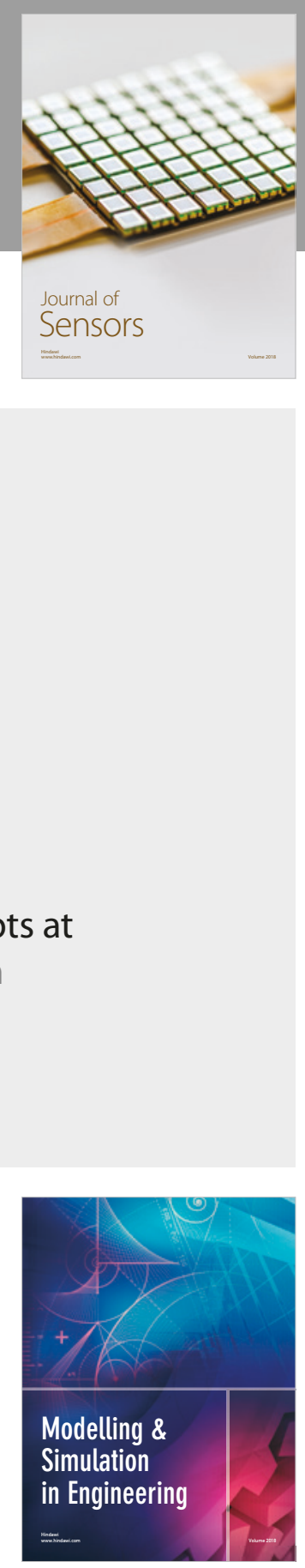

\section{Advances \\ Multimedia}
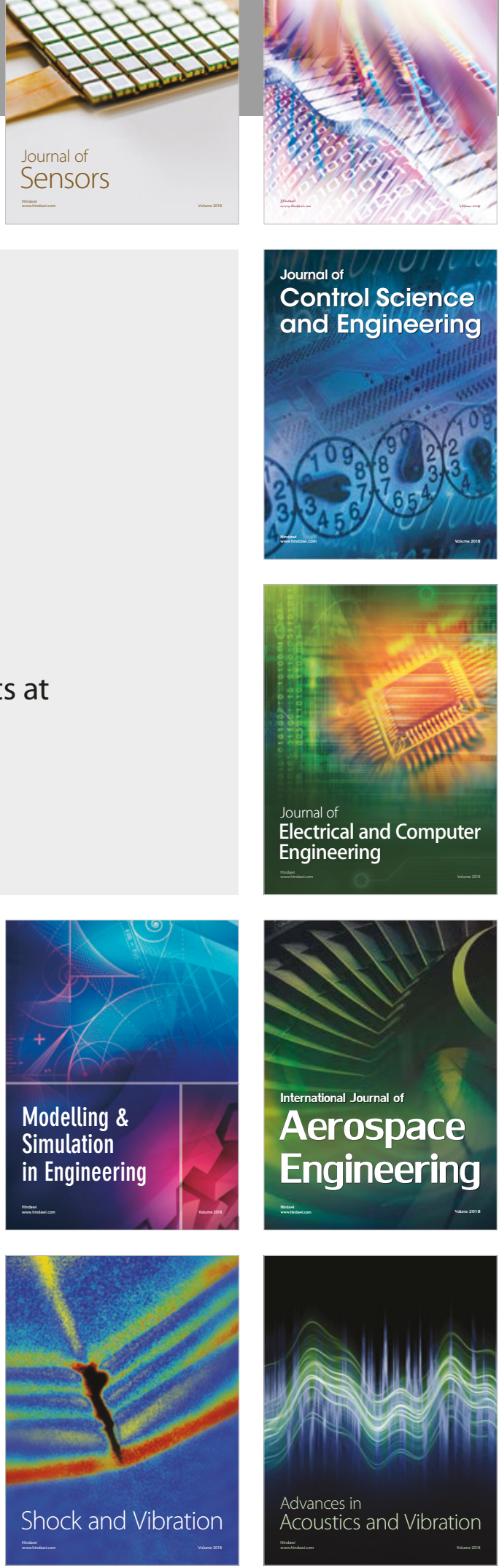